\title{
Aggregation of Order Picking System Using Order Batching
}

\author{
L. Suresh Raj ${ }^{1}$, R. Jeya Girubha ${ }^{2}$ \\ ${ }^{1}$ Post Graduate Student, Anna University Regional Centre, Coimbatore, Tamil Nadu, India \\ ${ }^{2}$ Teaching Assistant, Anna University Regional Centre, Coimbatore, Tamil Nadu, India
}

\begin{abstract}
The objective of this project is to know about the Order Picking System (OPS) in the warehouse management system (WMS). Order picking is a continuous process in distribution center. Before the picking process being carried out for a large set of orders, batching of customer orders can accelerate the order picking process. Hence in this project the OPS are carried out using order batching, the order picking is done by picker to parts method. This picker to part method is being done using various routing strategies, which is performed by heuristic algorithm. The order batching is performed using the savings algorithm. The order picking process is done for various routing strategies with batching and without batching. The comparison of routing strategies with batching and without batching is done for multiple cross aisle. The routing strategies are done using the interactive warehouse. The optimization using Vehicle Routing Problem (VRP) will reduce the warehouse operating cost and time taken to pick the orders.
\end{abstract}

Keywords: Order picking system, Order batching, Savings algorithm, Vehicle routing problem.

\section{Introduction}

Order picking is a warehouse function dealing with the retrieval of articles from their storage locations in order to satisfy a given demand specified by customer requests. Of all warehouse operations, order picking is considered to include the most cost intensive ones [1]. Up to $50 \%$ of the total warehouse operating costs can attributed to order picking [2]. Between the time an order is released to the warehouse and the time it takes to reach its destination, there is ample opportunity for errors in both accuracy and completeness, not to mention time lost. There is also room for improvement. Industry has come up with innovative solutions, making it possible to attain productivity up to 1,000 picks per person hour [3]. Among such manual order picking system, picker to parts systems can be considered as the most important ones. The order picking process to be more efficient then the picking operations and order batching are important. Today there are several order batching methods that tend to make efficient batching for the picking operations but the perfect method to form the batching requires a lot of considerations. The new developed technique still requires some progress to form a possible approach for the batching of customer orders. The ultimate aim of the batching is to reduce the time involved in the picking operation which can reduce the warehouse operating cost and also the order fulfillment will be at a great level.

\section{Literature Review}

The order picking process by manual picking enables the picker to pick the required item of the customer order hence the literature review has been carried out for various routing heuristics that give a clear idea about the order picking using routing heuristics. The warehouse order pickers walk or drive along the aisles to pick products from storage the branch and bound algorithm that performs the routing heuristics for picking process [4]. The order batching by seed and savings algorithms that tends to make an efficient batching for numerous instanced but the batching need to be first come first serve and also the availability of the product [5]. For off-line order batching the NP-hardness of the problem of minimizing the total travel time, if the number of orders per batch is greater than two and present a branch-and-price algorithm with column generation that was able to solve small instances to optimality in reasonable computing time[6].For larger off-line problems the use of heuristics is still advisable. These heuristic approaches can be distinguished in four groups. The first ones are priority rule-based algorithms, where orders are ranked according to a priority value and then are assigned to batches following this rank (FCFS) [7]. The second group consists of seed algorithms, which generate batches sequentially. They select one order as a start order for a batch. Additional orders are assigned to that batch according to an order-congruency rule [8]. Order batching has been proven to be pivotal for the efficiency of order picking operations. Improved order batching reduces the total picking time required to collect the requested articles it focus on order batching that is done by static and dynamic batching are the predominant ones [9]. The order batching is carried using the seed and time savings from which gives an efficient batching for grouping of order that can be made easy to pick for the order picker. The order batching is done for various instances to group the customer's order [10]. Methods of the third group, savings algorithms, are based on the Clarke-and-Wright-Algorithm for the Vehicle Routing Problem and have been adapted in several ways for the 
Order Batching Problem. For each pair of orders, the savings can be obtained by collecting the items of the two orders in one (large) tour instead of collecting them in two separate tours [11].

\section{Problem Identification}

The order picking process that is performed using routing heuristics can be made easy by effectively batching the orders. The order batching reduces the routing distance by picking the two orders in a single pick tour. The batching considerably reduces the pickers pick distance by getting a new route due to the combination of batching. Normally the batching is done by joining two orders but simply joining them doesn't give a better pick distance hence the Clarke and Wright Savings Algorithm gives an optimal savings for the effective batching of orders.

\section{The Clarke And Wright Algorithm}

The Clarke and Wright algorithm [11] is the most popular heuristic algorithm for the VRP. The algorithm calculates all the savings $S_{i j}$ between the order $i$ and $j$. assuming that $D_{i j}$ is the distance of travelling order $\mathrm{i}$ to $\mathrm{j}$. the following is a description of the Clarke and Wright algorithm to solve the VRP.

$R_{\mathrm{a}}=\mathrm{D}_{0 \mathrm{i}}+\mathrm{D}_{\mathrm{i} 0}+\mathrm{D}_{0 \mathrm{j}}+\mathrm{D}_{\mathrm{j} 0}$

$\mathrm{R}_{\mathrm{b}}=\mathrm{D}_{0 \mathrm{i}}+\mathrm{D}_{\mathrm{ij}}+\mathrm{D}_{\mathrm{j} 0}$

By combining the two routes one obtains the savings $S_{\mathrm{ij}}$ :

$S_{i j}=R_{a}-R_{b}=D_{i 0}+D_{0 j}-D_{i j}$

Step 1: Compute the savings $S=D_{i 0}+D_{0 j}-D_{i j}$

Step 2: Create the savings list. Process the savings list in each batch of order $\mathrm{i}$ to $\mathrm{j}$

Case 1: None of the two orders has been assigned to it.

If neither $\mathrm{i}$ nor $\mathrm{j}$ have already been assigned to a batch, then a new batch is initiated including both $\mathrm{i}$ and

Case 2: One of the orders has already been assigned to a batch; the other one will then added to the batch if the remaining capacity is sufficient; otherwise the next pair of orders will be considered.

If exactly one of the two order ( $i$ or $j$ ) has already been included in an existing batch and that order is not included to that batch

Case 3: Both orders have already been assigned; then the next pair of orders is considered

If both $\mathrm{i}$ and $\mathrm{j}$ have already been included in a two different batch, then the next pair of order is taken.

Step 3: If the savings list $S_{\mathrm{ij}}$ is not over repeat step 2, take the next customer order in the list: otherwise stop

\section{Case Study}

The order batching is done with the set of customer order list which is shown in the Table 1. Her sample of ten customer order is taken and the items location for the customer order is taken into account with the help of interactive warehouse of Kees Jan Roodbergen [4]. The batching of two customer order is limited to a maximum of 12 items. The interactive warehouse helps to know the route to pick the item in a shortest way and by combining the two customer order a new route is created. Here the optimal route is taken for the batching. The combined route distance is formed in the matrix form as shown in the Table 2. Now the savings is done by using the Clark's and Wright savings algorithm [11].

\section{A. Application of algorithm}

The Clark's and Wright savings algorithm forms the savings on the basis of savings formula using the distance matrix the batching is done with the help of the heights savings from the each batch and also the above mentioned three cases are also considered.

Table 1. Customer order

\begin{tabular}{|c|c|}
\hline Order No & Items \\
\hline 1 & 3 \\
\hline 2 & 4 \\
\hline 3 & 2 \\
\hline 4 & 6 \\
\hline 5 & 4 \\
\hline 6 & 5 \\
\hline 7 & 8 \\
\hline 8 & 2 \\
\hline 9 & 4 \\
\hline 10 & 3 \\
\hline Total & 41 \\
\hline
\end{tabular}


The distance matrix shown in the Table 2 is obtained for the optimal routing technique for a maximum of 12 items per pick and also the customer order is taken as 10 orders per batch for which the savings algorithm is applied to from the batch. In spite of too complex to batch large customer order it is limited to 10 per batch and also the total number of items in the batch is a maximum of 60 items.

Savings $\mathrm{S}_{\mathrm{ij}}=\mathrm{D}_{\mathrm{i} 0}+\mathrm{D}_{0 \mathrm{j}}-\mathrm{D}_{\mathrm{ij}}$

$$
\mathrm{s}_{12}=24=31+43-50\left(\mathrm{~d}_{10}+\mathrm{d}_{02}-\mathrm{d}_{12}\right)
$$

Maximum savings

Savings batch 1

$\mathrm{S}_{110}=30$

$\mathrm{S}_{23}=42$

$\mathrm{S}_{34}=45$

$\mathrm{S}_{410}=47 \ldots \ldots \ldots \ldots$ max saving

$\mathrm{S}_{59}=26$

$\mathrm{S}_{610}=46$

$\mathrm{S}_{710}=44$

$\mathrm{S}_{810}=27$

$\mathrm{S}_{910}=34$

Batch 1 is $\mathrm{S}_{410}=47$

Savings batch 2 (orders 4 and 10 is left)

$\mathrm{S}_{13}=30$

$\mathrm{S}_{23}=42$ max saving

$\mathrm{S}_{37}=43$

$\mathrm{S}_{59}=26$

$\mathrm{S}_{68}=26$

$\mathrm{S}_{78}=37$

$\mathrm{S}_{89}=22$

Batch 2 is $S_{23}=42$

Savings batch 3 (orders 2, 3, 4 and 10 is left)

$\mathrm{S}_{17}=23$

$\mathrm{S}_{59}=26$

$\mathrm{S}_{68}=26$

$\mathrm{S}_{78}=37$

$\mathrm{S}_{89}=22$

max saving

Batch 3 is $\mathrm{S}_{78}=37$

Savings batch 4 (orders 2, 3, 4, 7, 8 and 10 is left)

$\mathrm{S}_{16}=22$

$\mathrm{S}_{59}=26 \ldots \ldots \ldots \ldots$ max saving

$\mathrm{S}_{69}=23$

Batch 4 is $S_{59}=26$

Only on batch is left $\mathrm{S}_{16}=22$

Batch 5 is $\mathrm{S}_{16}=22$

Table 2. Distance matrix of $\mathrm{D}_{\mathrm{ij}}$ (Maximum number of item is 12)

\begin{tabular}{|l|l|l|l|l|l|l|l|l|l|l|l|}
\hline $\mathrm{D}_{\mathrm{ij}}$ & 0 & 1 & 2 & 3 & 4 & 5 & 6 & 7 & 8 & 9 & 10 \\
\hline 0 & - & 31 & 43 & 52 & 60 & 28 & 57 & 73 & 37 & 36 & 55 \\
\hline 1 & & - & 50 & 53 & 66 & 39 & 66 & 81 & 52 & 46 & 56 \\
\hline 2 & & & - & 53 & 63 & 47 & 70 & 79 & 51 & 48 & 65 \\
\hline 3 & & & & - & 67 & 54 & 68 & 82 & 56 & 54 & 66 \\
\hline 4 & & & & & - & 63 & 83 & - & 71 & 64 & 68 \\
\hline 5 & & & & & & - & 67 & 76 & 49 & 38 & 57 \\
\hline 6 & & & & & & & - & - & 68 & 70 & 66 \\
\hline 7 & & & & & & & & - & 73 & 79 & 84 \\
\hline 8 & & & & & & & & & - & 51 & 65 \\
\hline 9 & & & & & & & & & & - & 57 \\
\hline 10 & & & & & & & & & & & - \\
\hline
\end{tabular}


The maximum savings is 47 of the entire possible batch so the $\mathrm{S}_{410}$ is batched. For the next batch again see for maximum savings in the savings list and also leave the 4 th and $10^{\text {th }}$ order because it is all ready batched. Repeat the batching process until all the orders are batched. If any order that doesn't get batched due to maximum items limit then the order is pushed to the next batching order list.

According to the savings algorithm the batching is done and the 10 customer order shown on Table1 is batched as $S_{16}, S_{23}, S_{410}, S_{59}$ and $S_{78}$. The batching using the Clark's and Wright savings algorithm gives a better savings than the other batching process.

Table 3.Comparisons of without batching, FCFS and C\&W VRP

\begin{tabular}{|c|c|c|c|c|}
\hline Order & Items & $\begin{array}{c}\text { Distance } \\
\text { without } \\
\text { batching }\end{array}$ & $\begin{array}{c}\text { Distance } \\
\text { with } \\
\text { batching } \\
\text { FCFS }\end{array}$ & $\begin{array}{c}\text { Distance with } \\
\text { batching } \\
\text { Savings by VRP }\end{array}$ \\
\hline 1 & 41 & 472 & 314 & 298 \\
\hline 2 & 44 & 486 & 320 & 302 \\
\hline 3 & 45 & 490 & 336 & 306 \\
\hline 4 & 48 & 504 & 342 & 310 \\
\hline 5 & 49 & 512 & 356 & 318 \\
\hline 6 & 50 & 520 & 358 & 322 \\
\hline 7 & 50 & 526 & 360 & 338 \\
\hline 8 & 52 & 532 & 366 & 342 \\
\hline 9 & 52 & 536 & 370 & 354 \\
\hline 10 & 54 & 560 & 382 & 360 \\
\hline Total & 485 & 5138 & 3504 & 3250 \\
\hline
\end{tabular}

\section{Result And Discussion}

The order batching is done for the customer orders with the savings algorithm of Clark's and Wright and the savings is compared with the savings of the FCFS batching process. The batching comparison is shown in the Table 3 for the ten customer order and also the number of items is limited to a maximum of 12 items in a batch so the batching process for the 10 customer orders is limited to a maximum of 60 items are considered for the batching process if it exceeds the maximum limit means then the particular customer order is moved to the next batch.

\section{Conclusion}

The order picking system and its functions in the warehouse is known. The order batching for a given set of order is batched using the Clark's and Wright savings algorithm. The savings algorithm which uses the VRP makes the batching more efficient and gives a better time savings to pick the order. The batching is also limited for a certain extant due to the picking process may get complex. The comparison between the first come first serve and the savings algorithm using VRP is analyzed.

\section{References}

[1]. Petersen, C.G \& Schmenner, R.W. (1999): An Evaluation of Routing and Volume-based Storage Policies in an Order Picking Operation. Decision sciences 30(2), 481-501.

[2]. Frazelle, E. (2002): World-Class Warehousing and Material Handling, McGraw-Hill: New York.

[3]. K.J. and De Koster, R., Roodbergen, K.J. (2007), Design and control of warehouse order picking: a literature review. European Journal of Operations Research 182(2), 481-501.

[4]. Roodbergen, K.J. and De Koster, R., (2001), Routing methods for warehouses with multiple cross aisles, International Journal of Production Research, 39(9), 1865-1883.

[5]. Ducki, G., Oluic, C. (2004) Order Picking Routing Policies: Simple heuristics, advanced heuristics or optimal algorithm. Journal of Mechanical Engineering 50930, 327-331.

[6]. Gademann, N and S. van de velde (2005). Order Batching to Minimize Total Travel-Time in a parallel-Aisle Warehouse IIE Transactions 37(1), 63-75.

[7]. Gibson, D. R., and Sharp, G. P., 1992, Order batching procedures. European Journal of Operations Research, 58(1), 57-67.

[8]. Ho, Y.-C., T.-S. Su, and Z.-B. Shi (2008). Order Batching Methods for an Order Picking Warehouse with two Cross Aisles. Computers and Industrial Engineering 55(2), 321-347.

[9]. Sebastian Henn., 2011, Order Batching in Order Picking Warehouses: A Survey of Solution Approaches Working paper No. 01/2011 ISSN 1615-4274.

[10]. De koster, M.B.M., Poort, van der, E and Wolters, M.. (1999). Efficient Order Batching Methods in Warehouses. International Journal of Production Research, 1479-1504

[11]. G. Clarke, J. Wright, (1964). Scheduling of vehicles from a central depot to a number of delivery points, Operations Research, 12(4), 568-581. 